\title{
DISAGREEMENT ON THE GAIN SHARING METHOD IN SUPPLY CHAIN COLLABORATIONS
}

\author{
V.JUNG, M. PEETERS, T. VREDEVELD \\ Maastricht University School of Business and Economics, The Netherlands
}

\begin{abstract}
Due to a constantly growing competition among organizations and higher customer expectations, in the course of the last decades companies started to realize the need for supply chain collaboration (SCC). However, setting up a coalition is often challenging for collaborative parties. One major challenge for the implementation and success of a collaboration is a fair allocation method, which is accepted by and satisfies all collaborative parties. Although researchers already outlined the importance of the parties' acceptance of the gain sharing method, until now the actual acceptance levels of gain sharing methods have not been investigated. This paper fills this gap by investigating the acceptance levels of selected gain sharing methods in vertical three-echelon SCCs in the Dutch fast moving consumer goods (FMCG) industry. In addition, the influence of behavioural decision-making aspects on the acceptance of allocation methods is observed in order to explain the cause of the acceptance or rejection of the gain sharing method. Results indicate that the acceptance of a gain sharing method depends on the information availability and cognitive biases. Furthermore, due to a different influence of available information and varying cognitive biases, no allocation method is accepted by all collaborative parties. Practical implications include to provide each party individually all relevant information to increase the parties' acceptance and to apply debiasing techniques to make the decisions more predictable.
\end{abstract}

Keywords: supply chain collaboration, gain sharing, behavioural decision-making.

JEL: C71, D61, L80.

\section{INTRODUCTION}

In the course of the last decades companies started to realize the benefits of setting up a supply chain collaboration (SCC). Various challenges such as a constantly growing competition among organizations and higher customer expectations forced companies to look outside their organizational boundaries to search for parties with whom they can

Postal Address: 4-6 Minderbroedersberg, Maastricht University School of Business and Economics, Maastricht, 6211 LK, The Netherlands

(c) V. Jung, M. Peeters, T. Vredeveld, 2018

https://doi.org/10.21638/spbu18.2018.404 
collaborate [Lambert, Emmelhainz, Gardner, 1996; Simatupang, Sridharan, 2002; Cao, Zhang, 2011; Tan, 2002]. Nowadays, SCC is a widely discussed topic which can be defined as "two or more independent companies work jointly to plan and execute [...] operations with greater success than when acting in isolation" [Simatupang, Sridharan, 2002]. The greater success, which can be achieved through SCCs, has been outlined by several researchers such as [Lambert, Emmelhainz, Gardner, 1996; Cao, Zhang, 2011]. Examples are cost reduction reduction [Stank, Keller, Daugherty, 2001; Defryn, Vanovermeire, Sörensen, 2016], improved service performance and cycle time reduction [Stank, Keller, Daugherty, 2001].

Besides many possible competitive advantages, SCCs bring along challenges. According to [Cruijssen, Cools, Dullaert, 2007; Dahl, Derigs, 2011] as well as [Leng, Parlar, 2009], one main challenge for the implementation and the success of SCCs is the division of the coalition gain among the collaborative parties. If one party is not satisfied with its allocated share or has the feeling that it does not receive a fair portion of the coalition gain, future SCCs are less likely to occur [Jap, 2001].

In order to solve this problem, researchers developed different gain sharing methods to allocate the coalition gain among the collaborative parties. The general idea of these allocation methods is to distribute the gains in such a way that everyone is satisfied to ensure the establishment and sustainability as well as to realize the potential of the SCC [Liu, Wu, Xu, 2010]. Until now several allocation methods ranging from straightforward rules of thumbs to game theory-based methods have been proposed [Vanovermeire, Vercruysse, Sörensen, 2014]. The straightforward rules of thumbs are preferred in practice due to the fact that game-theoretical allocation methods are more difficult to understand, more complicated to compute and more data are required [Leng, Parlar, 2009]. One example for a straightforward rule of thumb is the equal allocation of the coalition gain among the parties [Jap, 2001]. Next to the equal allocation, methods where the weight for each party is determined based on e.g. the volume (i.e. the number of pallets, the total weight...) are often used in practice. Another possibility is to determine the weight according to the stand-alone costs [Vanovermeire, Vercruysse, Sörensen, 2014].

The allocation of the coalition gain clearly matches bargaining in a cooperative game. In the bargaining game a distribution problem for a fixed sum of resources has to be solved [Güth, Schmittberger, Schwarze, 1982; Suh, Wen, 2003]. As a result, several cooperative game theoretical based allocation methods exist. One example is a wellknown gain sharing method based on the foundation of cooperative game theory is the Shapley value, introduced by [Shapley, 1953]. Another example is the more complex cooperative game theoretic sharing mechanism called the nucleolus, introduced by [Schmeidler, 1969]. One more example is suggested in [Tijs, Driessen, 1986]. In their article, the researchers discuss an allocation method that first divides the costs in a separable and non-separable part. The separable part is directly linked and assigned to a specific party. The remaining costs, the nonseparable part, have to be divided among the parties. Besides, paper [Tijs, Driessen, 1986] mentions different ways of how the non-separable part of the costs can be allocated. Authors discuss the equal charge method (ECM), the alternative cost avoided method (ACAM) and the separable cost remaining benefits (SCRB), as well as introduce a new method, the cost gap method (CGM). Furthermore, [Frisk et al., 2010] introduce the equal profit method (EPM), where the maximum difference between the relative savings of two parties is minimized.

As each allocation method has its own advantages as well as disadvantages, if remains ambiguous which gain sharing method should be applied in a SCC compromised of parties with different objectives. However, as already outlined by [Cruijssen, Cools, Dullaert, 2007; Dahl, Derigs, 2011] along 
with [Leng, Parlar, 2009] the acceptance of a gain sharing method by all parties is necessary for the implementation and the success of a SCC. This is also stressed by several statements from the industry. For instance, manufacturers, logistics service providers as well as retailers from the Dutch fast moving consumer goods (FMCG) industry outlined the acceptance as well as satisfaction with the received gain is a major barrier for the implementation and the success of the collaboration. One retailer mentioned that he is "just willing to collaborate if there are real monetary gains for him" (interview with one retailer, 28.04.2015). In addition, another retailer pointed out that collaborations between the supply chain parties are only possible if all involved parties have the feeling of receiving a fair share of the total gain (interview with one retailer, 29.04.2015). Although the importance of the acceptance of the allocated gain and therefore the gain sharing method itself for the implementation and the sustainability of a SCC has been outlined in theory as well as practice, until now no researcher has investigated the acceptance levels of different gain sharing methods.

This paper tries to fill this gap and extends the work by [Cruijssen, Cools, Dullaert, 2007] and [Leng, Parlar, 2009] by investigating the parties' acceptance levels of selected gain sharing methods in vertical three-echelon SCCs between one manufacturer, one logistics service provider (LSP) and one retailer in the Dutch FMCG industry. The FMCG industry is chosen since for parties in this industry SCCs are very important in order to survive on the market [de Kok, van Dalen, van Hillegersberg, 2015]. As a result, to ensure sustainable SCCs in the FMCG industry all collaborative parties have to be satisfied with and accept the assigned gain share.

In addition, the influence of behavioural decision-making aspects on the acceptance levels of these gain sharing methods is examined in order to investigate the cause of the acceptance or rejection of the gain sharing method. Special attention is paid to two behavioural decision-making aspects: information availability and cognitive biases. The focus is firstly on information availability since in the case studies introduced by [Jung, Peeters, Vredeveld, 2017] and also in a preliminary qualitative study with 20 companies of the Dutch FMCG industry (see Appendix A) a connection between the access of information and the gain sharing has been identified.

Secondly, cognitive biases are considered due to their close connection to information availability. Parties rely on cognitive biases if incomplete information are provided [Sterman, 1989]. The incorporation of behavioural research literature within supply chain management (SCM) literature, is another research contribution of this paper. For a long time, the predominant assumption in economics was that human beings are rational thinking agents, which implies that decisions are made in a rational and consistent way [Sterman, 1989]. However, human beings are bounded due to limitations in available time, information and cognitive capabilities [Simon, 1979]. They tend to rely on heuristics or cognitive biases to deal with complex problems [Schenk, 2011].

Until now, a wide range of cognitive biases have been identified. Among these is the recency bias, where people tend to put more weight on the latest information they get [Hallowell, Gambatese, 2010]. Another example is the so-called salience bias, where human beings tend to focus on the most easily-recognizable items or information of a concept and ignore the once which are not that visible [Schenk, 2011]. The choicesupportive bias is a bias, where people tend to feel positive about something they choose, even if the choice has a flaw [Mather, Johnson, 2000]. As a final example, the framing effect bias is named. According to [De Martino et al., 2006], human beings are remarkable vulnerable to the manner in which the options are presented, which is the socalled framing effect. Therefore, when facing a consequentially identical decision problem people's decisions may be contrary 
depending on how the options are presented; in a positive, in terms of gains, or in a negative, in terms of losses, "frame". Until now, limited research has been published in the logistics and supply chain management literature dealing with the influence of human behaviour, judgment and decision-making. However, to ensure practical validity it is necessary to incorporate behavioural research in studies [Tokar, 2010]. This is stressed by [Mantel, Tatikonda, Liao, 2006] who outline the increased understanding of decisions made in SCM by integrating behavioural decision-making literature with SCM literature.

In this paper the acceptance of selected gain sharing methods as well as the influence of behavioural aspects on the acceptance levels of these allocation methods is investigated through a quantitative case study approach. This approach shows similarities but also differences compared to the bargaining game approach introduced in the literature. The intention of a bargaining game is the same as for the chosen approach, which is to solve a distribution problem for a fixed sum of resources [Güth, Schmittberger, Schwarze, 1982; Suh, Wen, 2003]. However, in the presented research the goal is clearly on observing the acceptance levels of the different gain sharing methods and not the sharing process itself, which is the case in the bargaining game. Another difference is that in bargaining games perfect information are assumed [Güth, Schmittberger, Schwarze, 1982], whereas in the chosen approach the amount of information a party is receiving is changing and no assumption is made about having the perfect information. Furthermore, the players can make binding agreements before entering the game in a bargaining game [Nash, 1953] which is not the case in the chosen approach. To conclude this comparison, it can be outlined that the intention to distribute a gain is the same for both approaches, but that the assumptions and settings are different.

The remainder of the paper is structured as follows. The research methodology is out- lined in Section 2. Next, in Section 3, the statistical analysis and the results are presented, followed by a discussion as well as directions for further research in Section 4. The paper concludes with an outline for practical as well as theoretical implications in Section 5.

\section{RESEARCH PROCEDURE}

To the best of the authors' knowledge, no researcher investigated the acceptance levels of gain sharing methods in practice. Therefore, this research is exploratory and the best-suited approach is a case study approach [Yin, 2013], more precisely a quantitative case study approach is used. By means of the case study the following questions will be examined:

1. What are the acceptance levels of gain sharing methods in the Dutch FMCG industry?

a. What are the manufacturers' acceptance levels of gain sharing methods?

b. What are the LSPs' acceptance levels of gain sharing methods?

c. What are the retailers' acceptance levels of gain sharing methods?

2. What is the influence of behavioural decision-making aspects on the acceptance levels of gain sharing methods in the Dutch FMCG industry?

a. What is the influence of information availability on the acceptance levels of gain sharing methods?

b. What is the influence of cognitive biases on the acceptance levels of gain sharing methods?

The research procedure is divided into four steps. In Table 1, the main aspects for each step are outlined.

\subsection{Variable selection}

In order to answer the outlined questions, the influence of three aspects - gain sharing method, information availability and perspective - on the acceptance of selected 
Table 1

\section{Research Procedure}

\begin{tabular}{|c|c|c|c|}
\hline Step & Procedure & Comments & Reference \\
\hline Step 1 & $\begin{array}{l}\text { Variable } \\
\text { selection }\end{array}$ & $\begin{array}{l}\text { Independent variables } \\
\text { Gain sharing method (Nucleolus, Shapley value, Weighted charge } \\
\text { method - Power/Initiator, Equal charge method) } \\
\text { Information availability (Phase 1, Phase 2, Phase 3) } \\
\text { Perspective (Manufacturer, LSP, Retailer) } \\
\text { Dependent variable } \\
\text { Acceptance }\end{array}$ & Section 3.1 \\
\hline Step 2 & $\begin{array}{l}\text { Data } \\
\text { collection }\end{array}$ & $\begin{array}{l}\text { Participants evaluate whether to accept or reject a certain gain share } \\
\text { for each of the five gain sharing methods in each of the three phases } \\
\text { Only outcomes (ordered from the lowest to the highest) are presented, } \\
\text { it is not mentioned which method is applied }\end{array}$ & Section 3.2 \\
\hline Step 3 & $\begin{array}{l}\text { Popula- } \\
\text { tion and } \\
\text { sample } \\
\text { selection }\end{array}$ & $\begin{array}{l}\text { Population } \\
\text { Companies from the Dutch FMCG industry and participants } \\
\quad \text { in a specific logistics competition } \\
\text { Sample size } \\
\quad 4 \text { manufacturers, } 4 \text { LSPs, } 4 \text { retailers }\end{array}$ & Section 3.3 \\
\hline Step 4 & $\begin{array}{l}\text { Data } \\
\text { analysis }\end{array}$ & $\begin{array}{l}\text { Research question } \\
\text { What are the acceptance levels of different gain sharing methods and } \\
\text { what is the influence of different behavioural decision-making aspects } \\
\text { on the acceptance levels of these allocation methods? } \\
\text { Analytical tool } \\
\text { Logistic regression with penalized maximum likelihood estimation } \\
\text { Independent variables } \\
\text { Gain sharing method (Method): Categorical variable; Baseline: } \\
\text { Nucleolus } \\
\text { Information availability (Phase): Categorical variable; Baseline: } \\
\text { Phase } 1 \\
\text { Perspective (Type): Categorical variable, Baseline: Manufacturer } \\
\text { Dependent Variable } \\
\text { Acceptance: Binary variable }\end{array}$ & Section 3.4 \\
\hline
\end{tabular}

gain sharing methods is investigated. These aspects are outlined in detail in the next sections.

\subsubsection{Gain sharing method}

First, the influence of the gain sharing method, which represents the first variable, is investigated. The gain sharing method determines the gain which is assigned to each party. As these differ among the gain sharing methods, the level of acceptance of the allocation methods are most likely different which might uncover possible cognitive biases. In this research, the focus is on four gain sharing methods: the Shapley value, the Nucleolus and two methods based on separable and non-separable costs, the weighted charge method (WCM) and the equal charge method (ECM). For the WCM two weights are chosen. Therefore, in total five gain sharing methods are investigated. The first two allocation methods are wellknown game-theoretical based methods and the most preferred methods in theory [Moulin, 1988]. The last two respectively three allocation methods are most similar to what is already used in practice, which follows from the preliminary study (Appendix A).

Shapley value. For the Shapley value the formation of the grand-coalition $N$, which includes every party of the SCC, can be seen as a sequential process, where the parties 
of the SCC enter one by one. For every party $i$, the value is defined as the average marginal contribution of the party to every possible sub-coalition $S$ of the grand-coalition containing this party. The Shapley value is based on the four axioms formulated by [Shapley, 1953] and can be computed by:

$$
\begin{array}{r}
x_{i}=\sum_{S \subset N \backslash i} \frac{|S| !(|N|-|S|-1) !}{|N| !} \times \\
\times(c(S \cup i)-c(S)),
\end{array}
$$

where $x_{i}$ - the allocated gain for party $i$; $N$ - the grand-coalition (all parties included); $S$ - a sub-coalition; $|N|,|S|-$ the number of parties in a grand-coalition and sub-coalition, respectively; $c(S)$ - the costs of sub-coalition $S$.

Nucleolus. The nucleolus [Schmeidler, 1969] is based on the idea to minimize the maximum excess. The excess is the gain the parties in a sub-coalition $S$ obtain if they exit the grand-coalition $N$. For a sub-coalition $S$ given an allocation $x$ the excess is denoted as:

$$
e(x, S)=c(S)-\sum_{i \in S} x_{i},
$$

where $e(x, S)$ - the excess for a sub-coalition $S$ given an allocation $x$; $S$ - a sub-coalition; $x_{i}$ - the allocated gain for party $i ; c(S)-$ the costs of the sub-coalition $S$.

Weighted charge method. The WCM is based on the idea of [Tijs, Driessen, 1986] that the costs are at first split in a separable $\left(m_{i}=c(N)-c(N \backslash i)\right)$ and a non-separable part $\left(c(N)-\Sigma_{j} m_{j}\right)$. The non-separable part is divided among the parties according to some specific weight $w_{i}$. The allocation portion for a party $i$ is then computed as follows:

$$
x_{i}=m_{i}+\left(c(N)-\sum_{j} m_{j}\right) \cdot w_{i},
$$

where $x_{i}$ - the allocated gain for party $i$; $m_{i}, m_{j}$ - the separable part of the gain for party $i$ and $j$, respectively; $N$ - the grandcoalition (all parties included); $c(N)$ - the costs of the grand-coalition $N$; $w_{i}$ - specific weight for party $i$.

Based on the preliminary study (see Appendix A) two different kinds of weights have been identified, one based on the power position and one based on the initiator. In the Dutch FMCG industry the retailer is the most powerful party. Therefore, the highest weight with $w_{r}=0.5$ is assigned to the retailer. In comparison to the manufacturer the logistics service provider is more powerful therefore, a weight of $w_{l}=0.3$ is assigned to the LSP and the rest $w_{m}=0.2$ is assigned to the manufacturer. Furthermore, in the Dutch FMCG industry often the LSP initiates to start the SCC. Therefore, the highest weight with $w_{l}=0.4$ is assigned to the LSP. The rest is equally split among the manufacturer and the retailer.

Equal charge method. The ECM is also based on the idea of [Tijs, Driessen, 1986]. In contrast to the WCM, the non-separable part is equally distributed among the parties. Therefore, the total amount allocated to each party $i$ is:

$$
x_{i}=m_{i}+\frac{c(N)-\sum_{j} m_{j}}{|N|},
$$

where $x_{i}$ - the allocated gain for party $i$; $m_{i}, m_{j}$ - the separable part of the gain for party $i$ and $j$, respectively; $N-$ the grandcoalition (all parties included); $|N|$ - the number of parties in a grand-coalition; $c(N)$ - the costs of the grand-coalition $N$.

\subsubsection{Information availability}

Second, the influence of the information availability, which represents the second variable, is examined. This behavioural decision-making aspect refers to the limitation of available information outlined by [Simon, 1979] in the context of bounded rationality. Human beings make their decisions based on cognitive biases when available information is limited [Sterman, 1989]. In order to investigate the influence of information availability, three different phases are developed, where the amount of information 
Table 2

Information about the financial consequences after a five-year supply chain collaboration

\begin{tabular}{l|c|c|c}
\hline & Manufacturer & Logistics service provider & Retailer \\
\hline Benefits & $€ 80000$ & $€ 50000$ & $€ 250000$ \\
\hline Costs & $€ 85000$ & $€ 10000$ & $€ 80000$ \\
\hline Profits & $-€ 5000$ & $€ 40000$ & $€ 170000$ \\
\hline
\end{tabular}

Table 3

Gain assigned to the different parties according to the gain sharing methods

\begin{tabular}{l|c|c|c}
\hline & Manufacturer & Logistics service provider & Retailer \\
\hline Nucleolus & $€ 4333.33$ & $€ 55333.33$ & $€ 145333.33$ \\
\hline Shapley & $€ 36333.33$ & $€ 61833.33$ & $€ 106833.33$ \\
\hline WCM-Power & $€ 41000.00$ & $€ 61500.00$ & $€ 102500.00$ \\
\hline WCM-Initiator & $€ 61500.00$ & $€ 82000.00$ & $€ 61500.00$ \\
\hline ECM & $€ 68333.33$ & $€ 68333.33$ & $€ 68333.33$ \\
\hline
\end{tabular}

\section{Market Information}

Retailer is the biggest player on the market with a market share of $25 \%$ and is a member of a union called "Super Unie". Relationships with this party are important.

LSP is a medium player on the market with a market share of $10 \%$.

Manufacturer is based locally (not international) and the goods are relatively easy to substitute.

Manufacturer is not a member of any association or union of parties from the same position

in the supply chain

Fig. 1. Market information for each party

increases with each phase. In the first phase, the participants only receive the information about their own financial consequences. This includes information about their expected benefits, the costs related to the SCC and the resulting expected profit, which is equal to the contribution they make to the coalition gain, see Table 2. Moreover, they receive the information about the gain they will receive according to each of the five gain sharing methods, see Table 3 . In the second phase, the participants also receive the information about the financial consequences of their coalition partners. Finally, in the last phase, market information for each collaborative party is included. Here information about the market share, the products and the importance of a collaboration with the party is included, see Fig. 1.

\subsubsection{Perspective}

Third, the influence of the perspective, which represents the third variable, is investigated. The case study focuses on a vertical SCC between one manufacturer, one LSP and one retailer. Different collaborative parties have different information and therefore, most likely show various cognitive biases [Sterman, 1989].

\subsection{Data collection}

The data of the quantitative case study have been collected using online surveys. The strong methodology control is the main reason to use an online survey. In an online survey the order of the questions, the completeness of the answers and the filtering can be controlled by the researcher [Evans, 
Mathur, 2005]. The participants are asked in each phase of information availability and for each gain sharing method to evaluate whether they would accept or reject the assigned gain. Thereby, the question order from Phase 1 to Phase 3 is necessary in order to observe the influence of available information. The participants only see the outcomes of the gain sharing method but they do not know which method is applied. Therefore, the acceptance of the allocation method is examined through the acceptance of the specific gain. The assigned gain shares are ranked from the lowest to the highest in order to prevent parties rejecting a gain share which is lower than one before.

Another important advantage of the online survey is that participants cannot look ahead like in a mail survey. However, in such a situation the questionnaire might appear to have an endless number of questions which might keep a respondent from continuing the online survey [Evans, Mathur, 2005]. In order to prevent this, a graphical progress indicator is used. The predetermined order and the prevention of looking ahead to later questions reduce the survey bias. Moreover, through the use of an online survey and not a personal survey or a telephone survey the so-called interview bias is avoided which can always occur when there is a personal contact between the interviewer and the respondent [Evans, Mathur, 2005]. The goal of the online survey is to among others observe cognitive biases, therefore, the prevention of biases resulting out of the surveys is essential. Furthermore, split samples are used. The online surveys differ per collaborative party, according to [Evans, Mathur, 2005] “online surveys are particularly effective when multiple samples are involved".

The online surveys are distributed through a link to the survey URLs in an e-mail. Reminders are sent out every week to achieve a higher response rate. An example of the online survey can be found in Appendix B.

\subsection{Population and sample size selection}

The online surveys are conducted with companies from the Dutch FMCG industry. This industry is selected due to the importance of SCCs for this industry [de Kok, van Dalen, van Hillegersberg, 2015]. In the FMCG industry it is necessary for parties to collaborate with their supply chain partners. To ensure sustainable SCCs, all parties have to be satisfied with and accept their assigned gain share. The participants are selected from a population of 26 companies participating in a logistic competition in the $\mathrm{Ne}^{-}$ therlands with the goal to reduce the truck cycle time at the retailer distribution centre through SCCs. The sample size is 12 including four manufacturers, four LSPs and four retailers. The online surveys were conducted with supply chain or logistics managers of the companies due to their experiences and expertise in SCC.

\subsection{Data analysis}

To analyse the outlined research questions a logistic regression is performed [Hosmer, Lemeshow, Sturdivant, 2013]. In order to use the logistic regression some data preparations have to be made. The dependent variable is a binary variable getting a value equal to 1 , if the gain is accepted and 0 , otherwise. The three independent variables are all categorical variables. The gain sharing method variable is coded as Nucleolus, Shapley, WCM-Power, WCM-Initiator and ECM. Taken the Nucleolus as a baseline, the gain sharing variable is represented by four binaries. To represent the five gain sharing methods only four design variables are necessary due to an intercept used in the model [Hosmer, Lemeshow, Sturdivant, 2013]. Information availability is represented by two variables with Phase 1 designated as the reference phase. The perspective is also represented by two variables and the Manufacturer is taken as the baseline. 
Problems with the logistic regression occurred as a consequence of the data pattern known as quasi-complete separation. Quasicomplete separation occurs if the dependent variable of an independent dummy variable is always either equal to 1 or to 0 . As a consequence, the maximum likelihood estimate does not exist. This problem often occurs if a small sample size is used [Allison, 2008]. Therefore, a logistic regression with penalized maximum likelihood estimation is used. The penalized maximum likelihood estimation method has been proposed by [Firth, 1993] to reduce the bias in maximum likelihood estimates. [Heinze, Schemper, 2002] show that this method provides a solution for the quasi-complete separation problem. The basic idea of the penalized maximum likelihood estimation method is to introduce a modified score function which removes the bias of the maximum likelihood estimates of the coefficients [Firth, 1993]. For a more elaborate explanation of this method, the reader is referred to [Firth, 1993; Heinze, Schemper, 2002].

The logistic regressions are performed using $R$ (version 3.3.2), using the package logistf. To perform the logistic regression with maximum likelihood estimation. The package logistf uses as a default the penalized log likelihood ratio test. As this method is also recommended by [Heinze, Schemper, 2002] for the logistic regression with maximum likelihood estimation, the penalized log likelihood ratio test is used.

The data analysis starts with a multicollinearity test. Based on the results of the multicollinearity tests the logistic regressions are performed. At first, the influence of all independent variables on the acceptance levels of the selected gain sharing methods is investigated. This is followed by the analysis of the influence of behavioural aspects on the acceptance level of each party separately to among others examine the questions (1a) to (1c). Therefore, three additional logistic regressions, one for the manufacturers, one for the LSPs and one for the retailers, are performed. Through an extensive comparison between the logistic regressions, differences in the parties' acceptance levels and the influence of behavioural aspects are identified. In Fig.2, an overview of the procedure of the data analysis is presented.

\section{STATISTICAL ANALYSIS AND RESULTS}

In the following the statistical analysis and the results are presented. At first, the results for the multicollinearity test are outlined. This is followed by the outcomes of the logistic regression where the influence of all independent variables on the acceptance levels is observed. Next, the results for each party separately are shown. In the remainder of this paper, a significance level of $5 \%$ is taken as the standard significance level.

\subsection{Multicollinearity}

One common problem when using multiple independent variables in a logistic regression is the occurrence of correlation among independent variables. When two independent variables are highly correlated, the problem known as multicollinearity occurs. Multicollinearity can seriously distort the interpretation of the model [Greene, 2003]. Table 4 shows the correlation matrix of the independent variables used in the logistic regression. All correlation coefficients have small values $(\leq 0.5)$ indicating no problems with multicollinearity. Therefore, all independent variables are included in the logistic regressions.

\subsection{Regression}

In this section, the acceptance levels of the gain sharing methods are investigated. In Fig. 3, the acceptance levels of the three parties over all gain sharing methods and phases are displayed. The overall business practitioners' acceptance level is $54.44 \%$. 


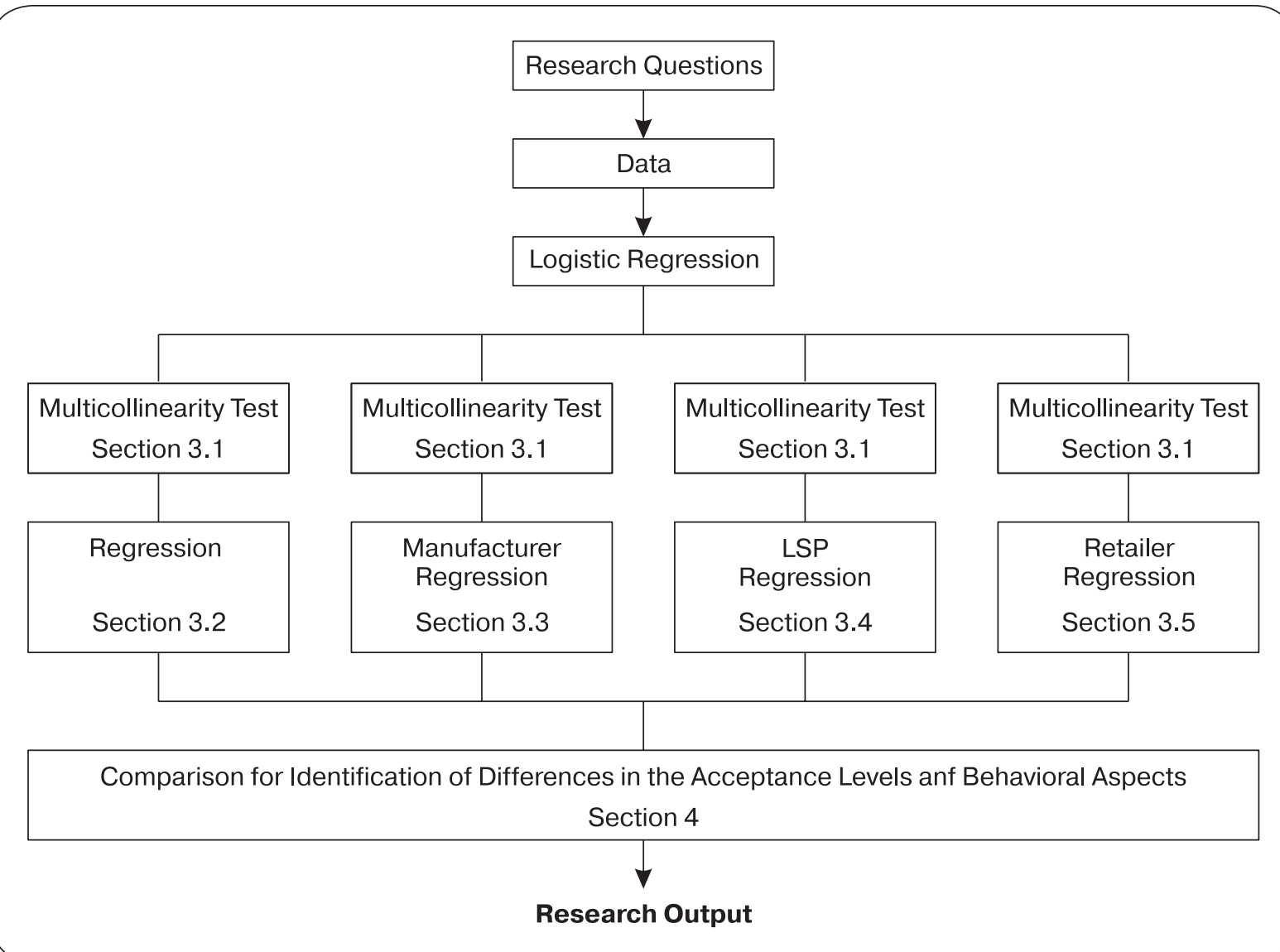

Fig. 2. Procedure of the data analysis

Table 4

Correlation matrix

\begin{tabular}{l|c|c|c|c|c|c|c|c|c|c|c}
\hline \multicolumn{1}{c|}{ Variable } & $\begin{array}{c}\text { Phase } \\
\mathbf{1}\end{array}$ & $\begin{array}{c}\text { Phase } \\
\mathbf{2}\end{array}$ & $\begin{array}{c}\text { Phase } \\
\mathbf{3}\end{array}$ & Nucleolus & Shapley & $\begin{array}{c}\text { WCM- } \\
\text { Power }\end{array}$ & $\begin{array}{c}\text { WCM- } \\
\text { Initiator }\end{array}$ & ECM & $\begin{array}{c}\text { Manu- } \\
\text { facturer }\end{array}$ & LSP & Retailer \\
\hline Phase 1 & 1.00 & -0.50 & -0.50 & -0.00 & -0.00 & -0.00 & -0.00 & -0.00 & -0.00 & -0.00 & -0.00 \\
\hline Phase 2 & & 1.00 & -0.50 & -0.00 & -0.00 & -0.00 & -0.00 & -0.00 & -0.00 & -0.00 & -0.00 \\
\hline Phase 3 & & & 1.00 & -0.00 & -0.00 & -0.00 & -0.00 & -0.00 & -0.00 & -0.00 & -0.00 \\
\hline Nucleolus & & & & 1.00 & -0.25 & -0.25 & -0.25 & -0.25 & -0.00 & -0.00 & -0.00 \\
\hline Shapley & & & & & 1.00 & -0.25 & -0.25 & -0.25 & -0.00 & -0.00 & -0.00 \\
\hline WCM-Power & & & & & & 1.00 & -0.25 & -0.25 & -0.00 & -0.00 & -0.00 \\
\hline WCM-Initiator & & & & & & & 1.00 & -0.25 & -0.00 & -0.00 & -0.00 \\
\hline ECM & & & & & & & & 1.00 & -0.00 & -0.00 & -0.00 \\
\hline Manufacturer & & & & & & & & & 1.00 & -0.50 & -0.50 \\
\hline LSP & & & & & & & & & & 1.00 & -0.50 \\
\hline Retailer & & & & & & & & & & & 1.00 \\
\hline
\end{tabular}

RMJ 16 (4): 537-562 (2018) 


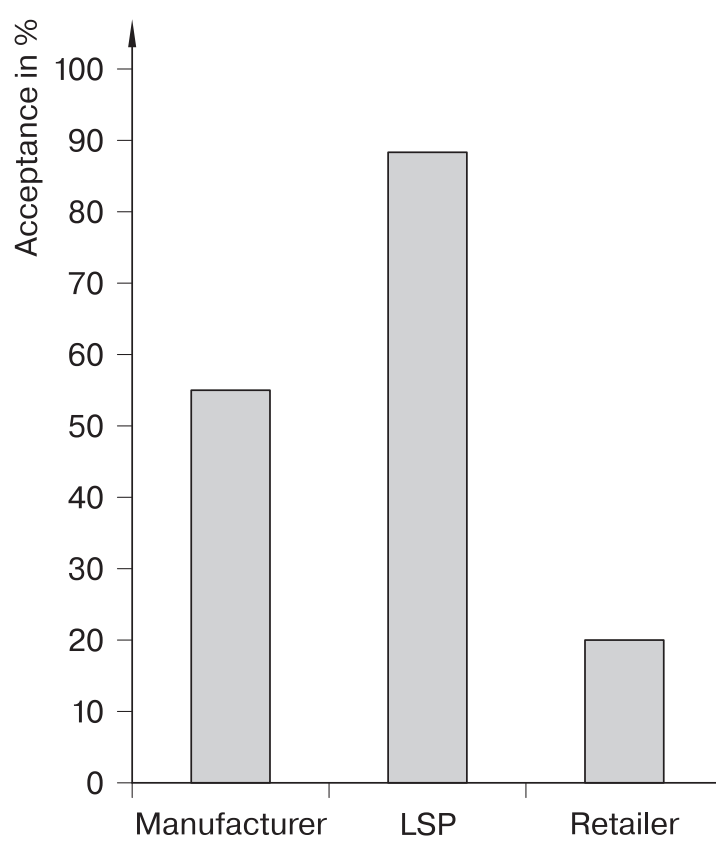

Fig. 3. Acceptance levels of each collaborative party

Looking at each party individually, the LSPs show the highest level of acceptance and the retailers the lowest. Moreover, the coefficient of the LSPs is positive. Therefore, in comparison to the manufacturers, the LSPs have a significantly higher level of acceptance at a $1 \%$ significance level. On the contrary, the retailers show a negative coefficient indicating a significantly lower acceptance level in comparison to the manufacturers even at a $1 \%$ significance level.

In Fig. 4, the acceptance levels of each of the five gain sharing methods in each phase are displayed. For the collaborative parties the Nucleolus reveals the smallest level of acceptance with on average $44.44 \%$ over three phases. This is also observed by the logistic regression, see Table 5. All allocation methods show a positive coefficient indicating that compared to the Nucleolus they have a higher level of acceptance. However, only the ECM shows a significant increase in the acceptance levels. Taken the phases into account, no significant difference between the phases is observed, see Table 5 .

\subsection{Regression manufacturer}

In Fig. 5, the manufacturers' acceptance levels of the five gain sharing methods in each phase are displayed. For the manufacturers, the overall level of acceptance is $55 \%$. Huge differences can be observed in the acceptance levels between the methods. Moreover, an increase in the acceptance from the Nucleolus to the ECM is noticeable. Therefore, the Nucleolus is the least accepted method with a level of acceptance of $8.33 \%$, averaged over the three phases. On the contrary, the most accepted method with an acceptance level of $100 \%$ is the ECM. In Table 6 , the results of the logistic regression are presented. A significant increase in the acceptance levels of the gain sharing methods compared to the Nucleolus is identified. Furthermore, a significant influence of the information availability on the acceptance levels is observed. Compared to Phase 1, the acceptance levels of Phase 2 and Phase 3 are significantly lower, with the lowest level of acceptance in Phase 2. 


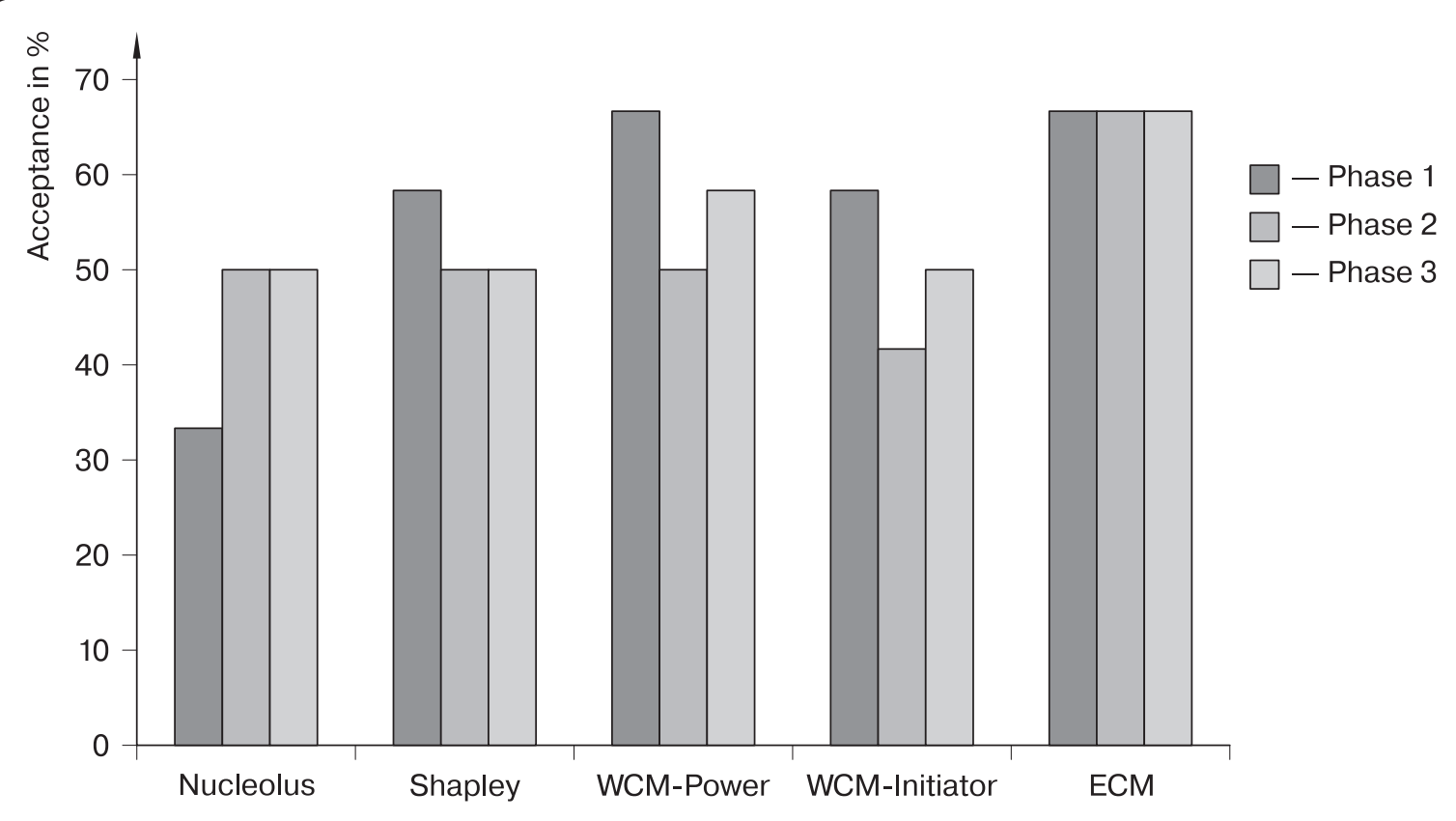

Fig. 4. Acceptance levels of the five different gain sharing method and the three different phases

Table 5

Logistic regression output for all collaborative parties

\begin{tabular}{|c|c|c|}
\hline & Coefficient & Significance level \\
\hline Intercept & $\begin{array}{c}-0.242 \\
(0.517)\end{array}$ & 0.633 \\
\hline Shapley & $\begin{array}{c}0.474 \\
(0.571)\end{array}$ & 0.399 \\
\hline WCM-Power & $\begin{array}{c}0.790 \\
(0.575)\end{array}$ & 0.161 \\
\hline WCM-Initiator & $\begin{array}{c}0.317 \\
(0.570) \\
\end{array}$ & 0.574 \\
\hline $\mathrm{ECM}$ & $\begin{array}{c}1.274 \\
(0.588)\end{array}$ & 0.025 \\
\hline Phase 2 & $\begin{array}{c}-0.287 \\
(0.444) \\
\end{array}$ & 0.512 \\
\hline Phase 3 & $\begin{array}{c}-0.096 \\
(0.444)\end{array}$ & 0.827 \\
\hline$\overline{\mathrm{LSP}}$ & $\begin{array}{c}1.769 \\
(0.472) \\
\end{array}$ & 0.000 \\
\hline Retailer & $\begin{array}{c}-1.564 \\
(0.421)\end{array}$ & 0.000 \\
\hline
\end{tabular}

$\mathrm{N}$ o t e: standard errors are in parentheses; statistics marked in bold indicate a significance of the corresponding independent variables. 


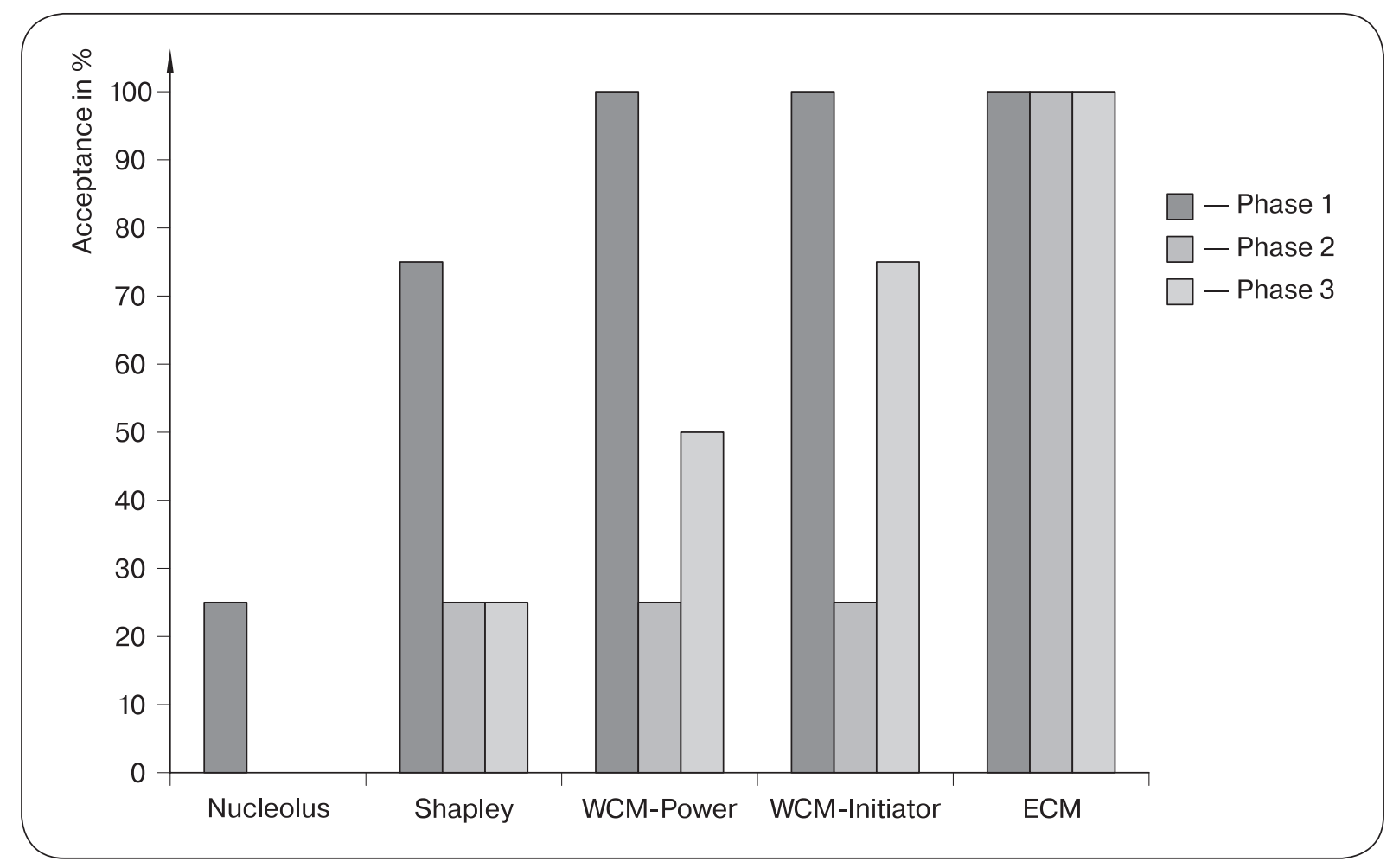

Fig. 5. Acceptance levels of the five different gain sharing method and the three different phases for the manufacturers

Table 6

Logistic regression output for the manufacturers

\begin{tabular}{|c|c|c|}
\hline & Coefficient & Significance level \\
\hline Intercept & $\begin{array}{c}-0.944 \\
(1.000)\end{array}$ & 0.292 \\
\hline Shapley & $\begin{array}{c}2.355 \\
(1.289)\end{array}$ & 0.037 \\
\hline WCM-Power & $\begin{array}{c}3.239 \\
(1.336)\end{array}$ & 0.003 \\
\hline WCM-Initiator & $\begin{array}{c}3.665 \\
(1.362)\end{array}$ & 0.001 \\
\hline$\overline{\mathrm{ECM}}$ & $\begin{array}{c}6.517 \\
(1.953)\end{array}$ & 0.000 \\
\hline Phase 2 & $\begin{array}{c}-3.152 \\
(1.073)\end{array}$ & 0.000 \\
\hline Phase 3 & $\begin{array}{c}-2.171 \\
(1.009)\end{array}$ & 0.015 \\
\hline
\end{tabular}

$\mathrm{N}$ ot e: standard errors are in parentheses; statistics marked in bold indicate a significance of the corresponding independent variables. 


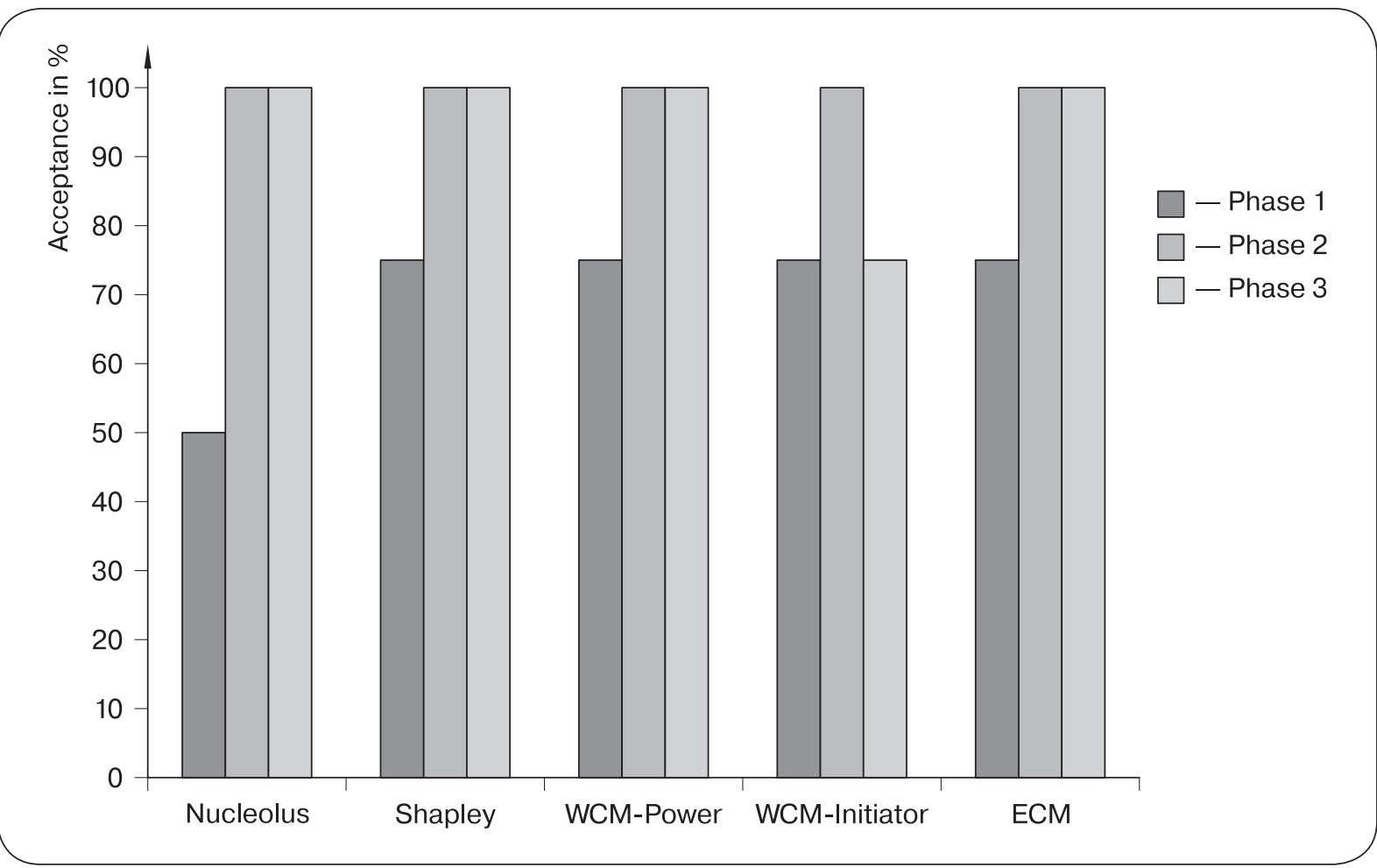

Fig. 6. Acceptance levels of the five different gain sharing method and the three different phases for the LSPs

\subsection{Regression LSP}

In Fig. 6, the LSPs' acceptance levels of the five gain sharing methods in each phase are displayed. The LSPs show a high overall acceptance level of $88.33 \%$ and for each allocation method acceptance levels of $75 \%$, averaged over the three phases, and higher are identified. Furthermore, differences in the acceptance levels of the phases are observed for the LSPs. A significant influence of the information availability on the acceptance levels is identified at a $10 \%$ significance level, see Table 7 . In addition, a positive influence of the information availability on the acceptance levels can be identified for the business practitioners.

\subsection{Regression retailer}

In Fig. 7, the retailers' acceptance levels of the five gain sharing methods in each phase are displayed. In total, the retailers have a low level of acceptance. They show a decrease in the acceptance from the Nucleolus to the ECM, with the lowest level of acceptance of the WCM-Initiator which is not accepted at all. The highest acceptance level is assigned to the Nucleolus with on avarage $41.67 \%$ over the three phases. Furthermore, a significant decrease in the acceptance compared to the Nucleolus is identified for the WCM-Initiator and the ECM at a $10 \%$ significance level, see Table 8. In total, no significant influence of the phases is observed (Table 8).

\section{DISCUSSION AND FURTHER RESEARCH}

\subsection{Result discussion}

The case studies revealed two main findings. First, the parties' acceptance of the gain 
Table 7

Logistic regression output for the LSPs

\begin{tabular}{l|c|c}
\hline & Coefficient & Significance level \\
\hline Intercept & $\begin{array}{c}0.296 \\
(0.854)\end{array}$ & 0.719 \\
\hline Shapley & $\begin{array}{c}0.710 \\
(1.236)\end{array}$ & 0.553 \\
\hline WCM-Power & $\begin{array}{c}0.710 \\
(1.236)\end{array}$ & 0.553 \\
\hline WCM-Initiator & $\begin{array}{c}0.000 \\
(1.121)\end{array}$ & 1.000 \\
\hline ECM & $\begin{array}{c}0.710 \\
(1.236)\end{array}$ & 0.553 \\
\hline Phase 2 & $\begin{array}{c}2.757 \\
(1.370)\end{array}$ \\
\hline Phase 3 & $\begin{array}{c}1.644 \\
(0.924)\end{array}$ & 0.010 \\
\hline \multicolumn{2}{c}{$\chi^{2}=11.722, \mathrm{~d} f=6, p$-value $=0.000$} \\
\hline
\end{tabular}

$\mathrm{N}$ ot e: standard errors are in parentheses; statistics marked in bold indicate a significance of the corresponding independent variables.

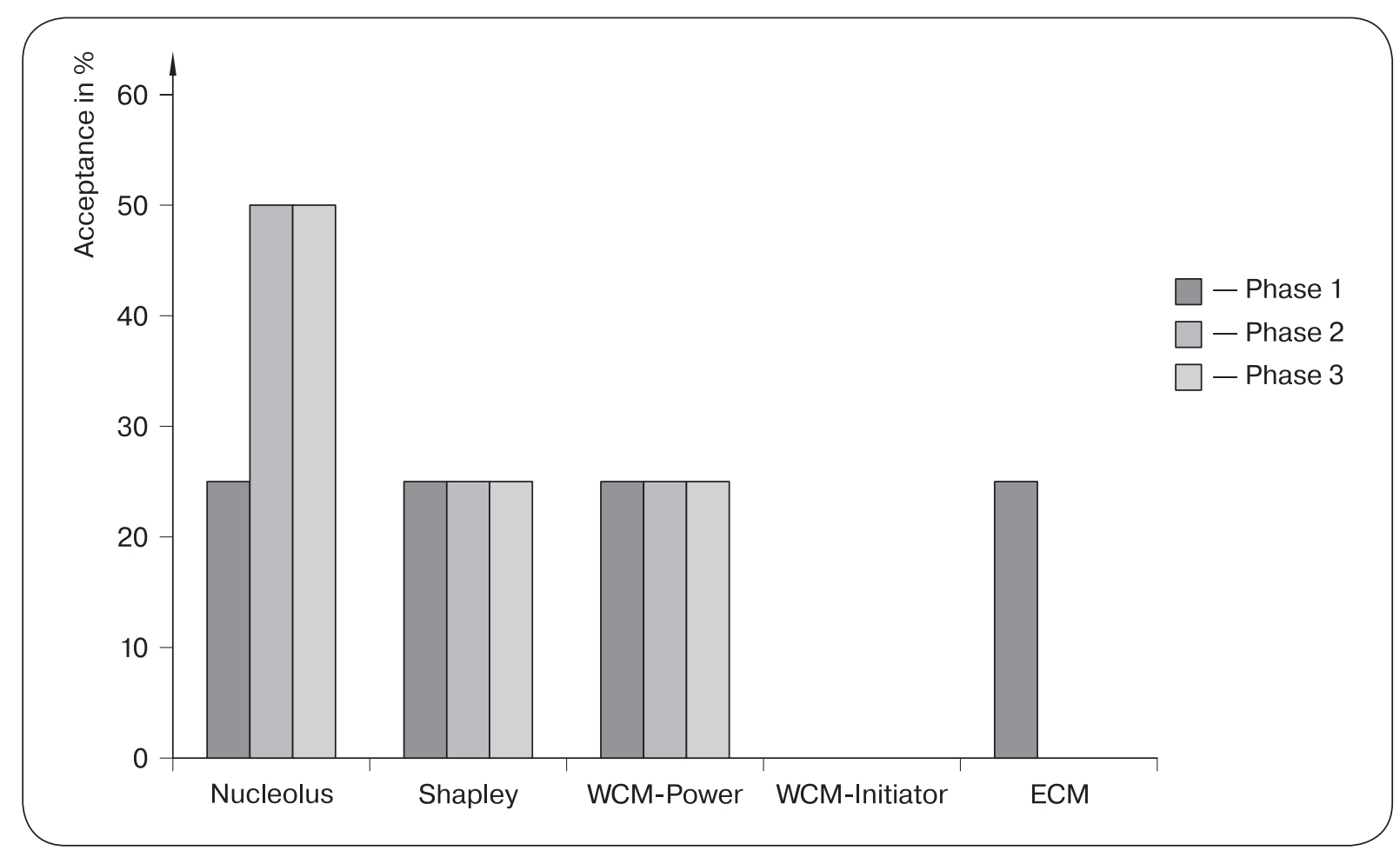

Fig. 7. Acceptance levels of the five different gain sharing method and the three different phases for the retailers 
Table 8

Logistic regression output for the retailers

\begin{tabular}{l|c|c}
\hline & Coefficient & Significance level \\
\hline Intercept & $\begin{array}{c}-0.296 \\
(0.742)\end{array}$ & 0.675 \\
& $\begin{array}{l}-0.659 \\
(0.869)\end{array}$ & 0.418 \\
\hline Shapley & $\begin{array}{c}-0.659 \\
(0.869)\end{array}$ & 0.418 \\
\hline WCM-Power & $\begin{array}{l}-2.830 \\
(1.552)\end{array}$ & 0.014 \\
\hline WCM-Initiator & $\begin{array}{c}-1.666 \\
(1.054)\end{array}$ \\
\hline ECM & $\begin{array}{c}0.000 \\
(0.793)\end{array}$ \\
\hline Phase 2 & 0.075 \\
& $\begin{array}{c}0.000 \\
(0.793)\end{array}$ \\
\hline Phase 3 & 1.000 \\
& \multicolumn{2}{c}{$\chi^{2}=10.601, \mathrm{~d} f=6, p$-value $=0.000$}
\end{tabular}

N o t e: standard errors are in parentheses; statistics marked in bold indicate a significance of the corresponding independent variables.

sharing method is influenced by available information and cognitive biases. Second, each party is differently influenced by the information availability and different parties reveal various cognitive biases. As a result of the different influence of information availability and varying cognitive biases, no allocation method is accepted by all collaborative parties. In the following for each party the influence of available information and cognitive biases on the acceptance decision is outlined. In addition, for each party separately and for all participants together, the preferred gain sharing method, which result from the influence of the behavioural aspects, is identified.

Results show the significant influence of the information availability for the manufacturers and the LSPs. However, the manufacturers are negatively influenced by the information availability, whereas the LSPs in the Dutch FMCG industry are positively influenced. For the manufacturers a significantly negative influence has been observed for Phase 2 even at a $1 \%$ significance level. In this phase, the manufacturers receive the information that normally the lowest gain share has been assigned to them omitting the fact that they are the smallest player in the supply chain. Last information was only provided in Phase 3. This information increased the acceptance level compared to Phase 2; nevertheless, the acceptance level of Phase 3 is below the one of Phase 1. Unlike the manufacturers, the LSPs in the Dutch FMCG industry are significantly positive influenced by available information. Unlike the manufacturers and LSPs, for the retailers no significant influence of available information could be identified.

In addition to the influence of the information availability, for all parties the influence of cognitive biases could be identified. Looking at the manufacturers' acceptance levels for the Nucleolus, apart from one manufacturer who accepted the gain share assigned by the Nucleolus in Phase 1, the allocation method has been rejected by all business practitioners, even though the assigned gain share with $€ 4333.33$ is greater compared to the manufacturer's contribution with $-€ 5000$. Therefore, 
an impact of cognitive biases can be assumed for the business practitioners. The manufacturers had to invest the highest amount to start the SCC, see Table 2. Taken this into account, the manufacturer's reason for rejecting the gain sharing methods might be the small portion of the gain that cannot justify the costs and efforts. The LSPs in the Dutch FMCG industry show the highest acceptance levels. This can be explained by the influence of a cognitive bias, the so-called choice-supportive bias [Mather, Johnson, 2000]. The LSPs are usually the party initiating to start the collaboration in the Dutch FMCG industry. Therefore, no matter what gain share is assigned, the LSPs always show a high acceptance level. On the contrary, the retailers reveal a very low acceptance level with $20 \%$. The low acceptance level of the retailers can be explained by the retailer's high contribution to the coalition gain combined with a lower gain according to all gain sharing methods, see Table 2 and Table 3. The missing influence of information availability on the acceptance levels indicate an additional influence of cognitive biases. One explanation might be the powerful position of the retailers in the Dutch FMCG supply chain, identified by [Jung, Peeters, Vredeveld, 2017]. Taking into account the power position of the retailers, this party might demand a bigger portion of the gain. [Tijs, Driessen, 1986] also outline that the choice of the method depends on the parties' power feeling. The WCM-Power already considers the party's power position; the highest weight has been assigned to the retailers. However, this allocation method revealed a low acceptance. Based on this result, it is assumed that the weight did not represent the retailer's power in the Dutch FMCG industry.

The above-mentioned findings clearly show that no party is influenced by available information in the same way and that different parties show various cognitive biases. Due to the different influence of information availability and varying cognitive biases, no allocation method is preferred by all collaborative parties. The manufacturers preferred the ECM with an acceptance level of $100 \%$. On the contrary, the retailers had a clear preference with $41.67 \%$ for the Nucleolus and the LSPs were indifferent between the Shapley value, the WCM-Power and the ECM. In addition, only small differences between the acceptance levels of the gain sharing methods for all parties together could be identified and the acceptance levels were far from $100 \%$. With an acceptance level of $66.67 \%$ the business practitioners showed a slight preference for the ECM. These findings confirm the result from literature that no gain sharing method is preferred by all collaborative parties [Tijs, Driessen, 1986] and demonstrate the challenge of applying a gain sharing method that is accepted by all collaborative parties which is, however, essential for the implementation and success of a SCC [Cruijssen, Cools, Dullaert, 2007; Cruijssen, Dullaert, Fleuren, 2007; Leng, Parlar, 2009; Cruijssen, 2012].

\subsection{Further research}

The present research offers several opportunities for further research. The small sample size represents one limitation of the quantitative case studies, but is balanced by the experiences and the expertise in regard to SCC of the respondent base. Furthermore, the results support statements in the literature that there exists no gain sharing method which is accepted by all collaborative parties and that decision-makers are influenced by available information and cognitive biases. Therefore, it is assumed that surveys with a greater sample size, in other industries and/or geographical areas will confirm the findings of this study. Moreover, the participants of the online survey were confronted with one specific artificial situation without e.g. monetary incentives. Conducting the online survey in a real-life situation could identify other important behavioural decision-making aspects. 
Furthermore, additional allocations methods and weights can be considered. In the study, four selected allocation methods have been tested; further research could also include gain sharing methods like the EPM or the WRSM in the survey. In addition, two weights, determined based on interviews, were taking into account in the survey. For the retailer it has been identified that the chosen weight for the WCM-Power is not representing its power position. Further research should, therefore, take into account also other important aspects of the FMCG industry and/or other industries as well as vary the weights assigned to the parties.

Moreover, two behavioural decision-making aspects were taken into account and debiasing techniques have been proposed. Further research could also take into account other aspects. One example is the availability of time, which is another component of the bounded rationality mentioned by [Simon, 1979]. The lack of available time force people to use heuristics or cognitive biases [Schenk, 2011; Simon, 1979], therefore, it might be interesting to also include the availability of time in future surveys. Furthermore, debiasing techniques should be tested in practice. Finally, it could be identified that due to the different influence of information availability and varying cognitive biases no gain sharing method is accepted by and satisfies all collaborative parties. Further allocation methods focusing on the parties' acceptance of and satisfaction with the assigned gain share might be one option to deal with the outlined problem.

\section{CONCLUSION}

SCC is used in many industries to gain competitive advantages. However, next to advantages, SCCs bring along challenges. In this paper, the focus was on the challenge of dividing the coalition gain among the collaborative parties. To increase the will- ingness of parties to join further SCCs and for the success of SCCs, it is important that every party is satisfied with and accepts the assigned amount of the coalition gain. The present paper investigated the acceptance levels of selected gain sharing methods in practice and is an extension of [Cruijssen, Cools, Dullaert, 2007; Leng, Parlar, 2009]. In [Cruijssen, Cools, Dullaert, 2007] authors identified the need for a fair gain allocation for the implementation and success of horizontal SCCs. In the context of vertical collaborations, [Leng, Parlar, 2009] confirmed the importance of a fair allocation method for parties to stay in the SCC. Although the acceptance of and satisfaction with a gain sharing method is necessary for a sustainable collaboration, until now the acceptance of these gain sharing methods in practice has not been examined. This paper filled this gap and enriches the SCM literature through the investigation of the acceptance levels of selected gain sharing methods in vertical three-echelon SCCs in the Dutch FMCG industry.

Another contribution to the SCM literature is the integration of behavioural decision-making literature. The predominant assumption for a long time was that decision-makers are rational thinking agents. However, decision-makers are human beings and therefore, their decisions are influenced by the bounded rationality and cognitive biases [Simon, 1979; Sterman, 1989; Schenk, 2011]. To ensure practical validity, it is necessary to incorporate behavioural research in studies [Tokar, 2010]. In this paper, two behavioural aspects, the information availability and cognitive biases, were taken into account and, therefore, novel insights in the understanding of the acceptance of the allocation methods are provided.

Results showed that providing the same information to all collaborative parties in the Dutch FMCG industry would lead to no preferred allocation method. As stated by [Cruijssen, Cools, Dullaert, 2007], a gain sharing method which is perceived as fair

RMJ 16 (4): 537-562 (2018) 
and is accepted by all collaborative parties is crucial for the implementation and success of the SCC. Therefore, one practical implication to overcome the barrier is to provide all relevant information to each party individually. Furthermore, differences between the different parties indicated the influence of various cognitive biases. Cognitive biases influence our rational behaviour resulting in unpredictable decisions [Schenk, 2011]. Therefore, in order to increase the predictability of the behaviour, one idea based on the research by [Soll, Milkman, Payne, 2015] is to apply so-called debiasing-techniques. One possible debiasing-technique is to provide all relevant information packaged in an intuitively comprehensible and compelling format.

\section{Acknowledgments}

This research was supported by the Combinatorial Optimization: Metaheuristics and EXact methods (COMEX) project. The authors would like to express sincere gratitude to Dr. Alexander Grigoriev from Maastricht University for his support as well as his valuable suggestions. Moreover, the authors would like to thank Etienne Wijler for his support with the statistical analysis as well as students from Maastricht University, Rob Demandt and Bastiaan Repetski, for conducting the online surveys with the companies from the Dutch FMCG industry. Finally, we thank two anonymous referees and the editors for helpful suggestions to improve the exposition of the paper.

\section{Appendix A}

The preliminary study consisted of 20 companies including 7 manufacturers, 6 LSPs and 7 retailers from the Dutch FMCG industry. All companies were also participating in the logistics competition, which is observed in this paper. For the data collection individual, semi-structured interviews were conducted mostly face-to-face with the supply chain managers from the companies. The following questions concerning the gain sharing methods were asked to the interviewees:

- What does "fair gain sharing" mean for you and your company?

- To what extend are you willing to share gains among the entire supply chain? (Answer on a 5-point Likert scale.)

In the following an example of the online survey is presented. This is an online survey for a participant party A, the manufacturer (Fig.8-9).

Fig. 10 to Fig. 12 show examples for the part of the online survey belonging to Phase 1. In Fig. 12 an example for the question in Phase 1 is shown. In the online survey in total five questions were asked; one for each gain sharing method.

Fig. 13 and Fig. 14 show examples for the part of the online survey belonging to Phase 2. In
- Would it be a problem for your company to share gains that are captured by your company, but are a result of a collaboration project with other parties involved? To what extend and why?

- If so, why are you willing to share gains? Mention your top 5.

- In your experience, how do other parties within your project/supply chain react to gain sharing?

- Before you start a collaboration project, is the transparency of how much each party needs to invest in collaboration projects an important issue?

- Before you are staring a collaboration project, is it crucial information for you to know how parties will benefit? To what extend and why?

Appendix $B$

Fig. 14 an example for the question in Phase 2 is shown. In the online survey in total five questions were asked; one for each gain sharing method.

Fig. 15 to Fig. 17 show examples for the part of the online survey belonging to Phase 3. In Fig. 17 an example for the question in Phase 3 is shown. In the online survey in total five questions were asked; one for each gain sharing method. 


\section{Behavioral Study - Party A}

$$
1 / 23
$$

havioral study.

Welcome to this behavioral study.

Please be sure to answer the questions the same way you would act in a real-life situation. The questionnaire will take you through different scenarios. More information will be presented as the questionnaire progresses. Please note that it will not be possible to go back once a question is answered.

Thank you for participating in our survey.

Your role: Party A

Fig. 8. Example of the online survey

\section{Behavioral Study - Party A}

$3 / 23$

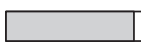

$3 / 23$

Fig. 8. Example of the online survey

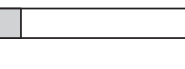

\section{Collaboration Project $X$}

Imagine you are party A in a vertical supply chain that involves three different parties (party A, party B and party C). A new opportunity has presented itself in the form of a collaboration project: Project X.

The goal of this project is to take advantage of the extra benefits resulting from the collaboration by getting different parties (party A, party B, party C) involved to work together and optimize supply chain operations. It is expected that the parties involved require different investments and the distribution of gains over the supply chain will not be proportional.

You will be presented with your individual benefits (gains), costs and profits and with the overall supply chain profit once all parties enter the collaboration. Please investigate this information carefully

Fig. 9. Example of the online survey

\section{Behavioral Study - Party A}

$$
4 / 23
$$

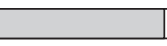

\section{Collaboration Project X}

\begin{tabular}{|l|l|l|}
\hline & Party A & Party B \\
\hline Benefits (expected gains) & $€ 80000$ & \\
\hline Costs (investments) & $€ 85000$ & \\
\hline Direct profit & $-€ 5000$ & \\
\hline Overall collaboration profit & & \\
\hline
\end{tabular}

The benefit (expected gain) and costs (investments) presented are your individual direct benefits and investments for the project. The profit presented would be your direct profit in case no gain sharing methods are applied.

The overall collaboration profit is the sum of all individual direct profits within the supply chain.

On the following pages, different gain sharing methods will be applied and a portion of the collaboration profit will be assigned to you. This assigned profit will replace your direct profit in the case of gain sharing

Fig. 10. Example of the online survey 


\section{Behavioral Study - Party A}

$5 / 23$

\section{Collaboration Project X}

Now you will be presented with different allocation scenarios for the supply chain profit resulting from the collaboration project. The allocation is the result of gain sharing methods that have been applied.

Please indicate whether you would accept or reject the presented solution

Fig. 11. Example of the online survey

\section{Behavioral Study - Party A}

$6 / 23$

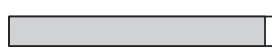

\begin{tabular}{|l|l|l|}
\hline & Party A & Party B \\
\hline Benefits (expected gains) & $€ 80000$ \\
\hline Costs (investments) & $€ 85000$ \\
\hline Direct profit & $-€ 5000$ \\
\hline Overall collaboration profit & \\
\hline
\end{tabular}

Would you accept the following portion of the overall collaboration profit (replacing your direct profit)?

\section{$€ 4333$}

Accept

Reject

Fig. 12. Example of the online survey

\section{Behavioral Study - Party A}

$11 / 23$

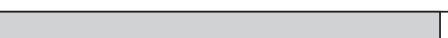

\section{Collaboration Project X}

Now you will be presented with the same allocation scenarios for the supply chain profit resulting from the collaboration project; however, you will get a transparent overview of the benefits (gains), costs and profits of the other parties involved. The allocation is the result of the gain sharing methods that have been applied.

Please indicate whether you would accept or reject the presented solution

Fig. 13. Example of the online survey 
Behavioral Study - Party A

$12 / 23$

$52 \%$

\begin{tabular}{|l|c|c|c|}
\hline & Party A & Party B & Party C \\
\hline Benefits (expected gains) & $€ 80000$ & $€ 50000$ & $€ 250000$ \\
\hline Costs (investments) & $€ 85000$ & $€ 10000$ & $€ 80000$ \\
\hline Direct profit & $-€ 5000$ & $€ 40000$ & $€ 170000$ \\
\hline Profit allocation & $€ 4333$ & $€ 55333$ & $€ 145333$ \\
\hline Overall collaboration profit & \multicolumn{3}{|c|}{$€ 205000$} \\
\hline
\end{tabular}

Would you accept the following portion of the overall collaboration profit (replacing your direct profit)?

\section{$€ 4333$}

Accept

Reject

Fig. 14. Example of the online survey

\section{Behavioral Study - Party A}

$17 / 23$

(20)

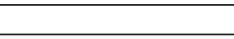

$74 \%$

\section{Collaboration Project X}

Now you will be presented with the same allocation scenarios for the supply chain profit resulting from

the collaboration project; however, you now not only get a transparent overview of the benefits (gains), costs and profits of the other parties involved, but also an idea of the market conditions. The allocation is the result of gain sharing methods that have been applied.

Please indicate whether you would accept or reject the presented solution

Fig. 15. Example of the online survey

\section{Behavioral Study - Party A}

$18 / 23$

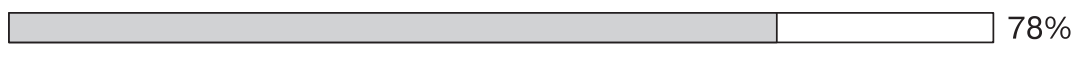

\section{Project X Assumptions}

Party $\mathrm{C}$ is the biggest player on the market with a market share of $25 \%$ and is a member of a union called "Super Unie". Relationships with this party are important.

Party $\mathrm{B}$ is a medium player on the market with a market share of $10 \%$.

Party $A$ is based locally (not international) and the goods are relatively easy to substitute. Party $A$ is not a member of any association or union of parties from the same position in the supply chain

Fig. 16. Example of the online survey

RMJ 16 (4): 537-562 (2018) 
Behavioral Study - Party A

$19 / 23$

$83 \%$

\begin{tabular}{|l|c|c|c|}
\hline & Party A & Party B & Party C \\
\hline Benefits (expected gains) & $€ 80000$ & $€ 50000$ & $€ 250000$ \\
\hline Costs (investments) & $€ 85000$ & $€ 10000$ & $€ 80000$ \\
\hline Direct profit & $-€ 5000$ & $€ 40000$ & $€ 170000$ \\
\hline Profit allocation & $€ 4333$ & $€ 55333$ & $€ 145333$ \\
\hline Overall collaboration profit & \multicolumn{3}{|c|}{$€ 205000$} \\
\hline
\end{tabular}

Party $\mathrm{C}$ is the biggest player on the market with a market share of $25 \%$ and is

a member of a union called "Super Unie".

Relationships with this party are important.

Party $\mathrm{B}$ is a medium player on the market with a market share of $10 \%$.

Party $A$ is based locally (not international) and the goods are relatively easy

to substitute. Party $A$ is not a member

of any association or union of parties from

the same position in the supply chain.

Would you accept the following portion of the overall collaboration profit (replacing your direct profit)?

\section{$€ 4333$}

Accept

Reject

Fig. 17. Example of the online survey

\section{REFERENCES}

Allison P. D. 2008. Convergence Failures in Logistic Regression. SAS Global Forum 2008.

Cao M., Zhang Q. 2011. Supply chain collaboration: Impact on collaborative advantage and firm performance. Journal of $\mathrm{Op}$ erations Management 29 (3): 163-180.

Cruijssen F. 2012. Collaboration Concepts for $\mathrm{CO}$-Modality $\left(\mathrm{CO}^{3}\right) . \mathrm{CO}^{3}$ position paper: Framework for collaboration.

Cruijssen F., Cools M., Dullaert W. 2007. Horizontal cooperation in logistics: Opportunities and impediments. Transportation Research Part E: Logistics and Transportation Review 43 (2): 129-142.

Cruijssen F., Dullaert W., Fleuren H. 2007. Horizontal cooperation in transport and logistics: A literature review. Transportation Journal 46 (3): 22-39.

Dahl S., Derigs U. 2011. Cooperative planning in express carrier networks - An em- pirical study on the effectiveness of a realtime Decision Support System. Decision Support Systems 51 (3): 620-626.

Defryn C., Vanovermeire C., Sörensen K. 2016. Gain sharing in horizontal logistics co-operation: A case study in the fresh fruit and vegetables sector. In: Lu M., De Bock J. (eds). Sustainable Logistics and Supply Chains; 75-89. Springer: N.Y.

De Martino B., Kumaran D., Seymour B., Dolan R.J. 2006. Frames, biases, and rational decision-making in the human brain. Science 313: 684-687.

de Kok A.G., van Dalen J., van Hillegersberg J. (eds). 2015. Cross-Chain Collaboration in the Fast Moving Consumer Goods Supply Chain. Eindhoven University of Technology: Eindhoven.

Evans J.R., Mathur A. 2005. The value of online surveys. Internet Research 15 (2): 195-219. 
Firth D. 1993. Bias reduction of maximum likelihood estimates. Biometrika 80 (1): 27-38.

Frisk M., Göthe-Lundgen M., Jörnsten K., Rönnqvist M. 2010. Cost allocation in collaborative forest transportation. European Journal of Operational Research 205 (2): 448-458.

Greene W.H. 2003. Econometric Analysis. 2nd ed. Pearson: London.

Güth W., Schmittberger R., Schwarze B. 1982. An experimental analysis of ultimatum bargaining. Journal of Economic Behavior and Organization 3 (4): 367388.

Hallowell M.R., Gambatese J.A. 2010. Qualitative research: Application of the Delphi method to CEM research. Journal of Construction Engineering and Management 136 (1): 99-107.

Heinze G., Schemper M. 2002. A solution to the problem of separation in logistic regression. Statistics in Medicine 21 (16): 2409-2419.

Hosmer D. W., Lemeshow S., Sturdivant R. X. 2013. Applied Logistic Regression. 5th ed. Wiley: N.Y.

Jap S. D. 2001. "Pie sharing" in complex collaboration contexts. Journal of Marketing Research 38 (1): 86-99.

Jung V., Peeters M., Vredeveld T. 2017. A Framework for Better Evaluations of Supply Chain Collaborations: Evidence from the Dutch Fast Moving Consumer Goods Industry. Working paper. Graduate School of the School of Business and Economics, Maastricht.

Lambert D. M., Emmelhainz M.A., Gardner J.T. 1996. Developing and implementing supply chain partnerships. International Journal of Logistics Management 7 (2): 1-18.

Leng M., Parlar M. 2009. Allocation of cost savings in a three-level supply chain with demand information sharing: A cooperative-game approach. Operations Research 57 (1): 200-213.

Liu P., Wu Y., Xu N. 2010. Allocating collaborative profit in less-than truckload car- rier alliance. Journal Service Science Management 3 (1): 143-149.

Mantel S.P., Tatikonda M.V., Liao Y. 2006. A behavioural study of supply manager decision-making: Factors influencing make versus buy evaluation. Journal of Operations Management 24 (6): 822-838.

Mather M., Johnson M.K. 2000. Choice-supportive source monitoring: Do our decision seem better to us as we age? Psychology and Aging 15 (4): 596-606.

Moulin H. 1988. Axioms of Cooperative Decision Making. Econometric Society Monographs. Cambridge University Press: N. Y.

Nash J.F. 1953. Two-person cooperative games. Econometrica 21 (1): 128-140.

Schenk D.H. 2011. Exploiting the salience bias in designing taxes. Yale Journal on Regulation 28 (2): 253-311.

Schmeidler D. 1969. The nucleolus of a characteristic function game. Journal on Applied Mathematics 17 (6): 1163-1170.

Shapley L. S. 1953. A value for n-person games. Annals of Mathematics Studies 28 (3): $307-$ 317.

Simatupang T.M., Sridharan R. 2002. The collaborative supply chain. International Journal of Logistics Management 13 (1): 15-30.

Simon H.A. 1979. Rational decision making in business organizations. American Economic Review 69 (4): 493-513.

Soll J.B., Milkman K.L., Payne J.W. 2015. A user's guide to debiasing. In: Keren G., Wu G. (eds). Wiley Blackwell Handbook of Judgment and Decision Making. Wiley: Chichester; 924-951.

Stank T.P., Keller S. B., Daugherty P. J. 2001. Supply chain collaboration and logistical service performance. Journal of Business Logistics 22 (1): 29-48.

Sterman J.D. 1989. Modelling managerial behavior: Misperceptions of feedback in a dynamic decision making experiment. Management Science 35 (3): 321-339.

Suh S.-C., Wen Q. 2003. Multi-Agent Bilateral Bargaining and the Nash Bargaining Solution. Working paper. Vanderbilt University. 
Tan K.C. 2002. Supply chain management: Practices, concerns, and performance issues. Journal of Supply Chain Management 38 (4): 42-53.

Tijs S.H., Driessen T.S.H. 1986. Game theory and cost allocation problems. Management Science 32 (8): 1015-1028.

Tokar T. 2010. Behavioural research in logistics and supply chain management. Inter- national Journal of Logistics Management 21 (1): 89-103.

Vanovermeire C., Vercruysse D., Sörensen K. 2014. Analysis of different cost allocation methods in collaborative transport settings. Journal of Engineering Management and Economics 4 (2): 132-150.

Yin R. K. 2013. Case Study Research: Design and Methods. SAGE: L.A.

Initial Submission: June 29, 2018

Final Version Accepted: November 26, 2018

\section{Несогласие относительно метода раздела выгод при сотрудничестве в цепях поставок}

\section{В.Юнг}

Аспирантка, Школа бизнеса и экономики Маастрихтского университета, Нидерланды

E-mail: verena_jung@yahoo.com

\section{М.Питерс}

Преподаватель, научный сотрудник, Школа бизнеса и экономики Маастрихтского университета, Нидерланды

E-mail:m.peeters@maastrichtuniversity.nl

\section{Т. Вредевелд}

Доцент, Школа бизнеса и экономики Маастрихтского университета, Нидерланды E-mail: t.vredeveld@maastrichtuniversity.nl

В последние десятилетия из-за постоянно растущей конкуренции среди организаций и все более высоких ожиданий клиентов компании стали осознавать необходимость сотрудничества в цепях поставок. Однако формирование коалиции зачастую становится вызовом для ее участников. Одной из наиболее серьезных проблем для функционирования и успешности коалиции является честный метод распределения выгод, признаваемый всеми ее участниками и удовлетворяющий их. Несмотря на то что исследователи уже продемонстрировали важность одобрения сторонами метода раздела выгод, до сих пор фактический уровень одобрения таких методов участниками цепей поставок не становился предметом анализа. Авторы статьи стремятся заполнить этот пробел в рамках исследования уровней одобрения нескольких выбранных методов раздела выгод на примере вертикальных трехуровневых цепей поставок в сфере товаров повседневного спроса в Дании. В работе также рассматривается воздействие поведенческих аспектов принятия решений на уровень согласия с методами раздела выгод - с целью объяснения причин принятия или непринятия определенного метода. Результаты анализа демонстрируют, что одобрение метода раздела выгод зависит от доступности информации и когнитивных предубеждений (biases). Кроме того, в связи с разным влиянием доступной информации и переменных когнитивных предубеждений ни один метод распределения выгод не одобряется сразу всеми сторонами, сотрудничающими в цепи поставок. Что касается практического применения полученных результатов, 
то можно рекомендовать предоставлять индивидуально каждому участнику всю существенную информацию для повышения уровня одобрения метода раздела выгод всеми сторонами, а также использовать подходы, позволяющие снижать уровень когнитивных предубеждений, чтобы сделать принимаемые участниками цепи поставок решения более предсказуемыми. Ключевые слова: сотрудничество в цепи поставок, раздел выгод, поведенческое принятие решений.

JEL: C71, D61, L80.

For citation: Jung V., Peeters M., Vredeveld T. Disagreement on the gain sharing method in supply chain collaborations. Russian Management Journal 16 (4): 537-562. https://doi. org/10.21638/spbu18.2018.404

https://doi.org/10.21638/spbu18.2018.404

Статья поступила в редакиию 29 июня 2018 г. Принята к публикации 26 ноября 2018 г. 